\title{
AUTOMATIC EXTRACTION OF FERROMAGNETIC PARTICLE FROM NON- HOMOGENEOUS SOLID-SOLID MIXTURE
}

\author{
M.F. ISMAIL, M.O. REZA, A.A. ROKONI AND M.A.R. SARKAR \\ Department of Mechanical Engineering, \\ Bangladesh University of Engineering and Technology, Bangladesh.
}

farhadananda.128@gmail.com

\begin{abstract}
Separation of magnetic particles in sand processing is very important for many industrial purposes. This paper presents an automation process to separate the magnetic particles from a non-homogeneous solid-solid mixture (sea sand). Here a magnetic force is created by changing the electric field and thus the particles are separated from the mixture of sand automatically. Here such a simple and cost effective design is prsented which can automatically take the the mixture as input and give the refined and separated product as output continuously.
\end{abstract}

ABSTRAK: Pengasingan zarah-zarah bermagnet dalam pemprosesan pasir penting untuk pelbagai tujuan industri. Kertas ini membentangkan proses pengautomatikan untuk mengasingkan butir-butir bermagnet dari pepejal tak homogen - campuran pepejal (pasir pantai). Di sini, daya magnet dihasilkan dengan menukarkan medan elektrik dan seterusnya butir-butir ini terasing daripada campuran pasir dengan sendirinya. Kaedah yang mudah dan rekaan keberkesanan kos ini secara langsung mengambil campuran tersebut sebagai input dan memberikan hasil bertapis dan terpisah sebagai output dengan berterusan.

KEYWORDS: magnetic particle; automation; non-homogeneous solid-solid mixture; magnetic force; continuously

\section{INTRODUCTION}

Magnetic separation is a process in which magnetically susceptible material is extracted from a mixture using a magnetic force. This separation technique is used here to separate magnetic particles from non-homogeneous solid-solid mixture such as sea sand. Engineers and researchers frequently need to carry out numerous experiments within a very short time. A highly automated system widens the scope of achieving an efficient result in a short period of time. Sand is an available natural resource. In sand there are good percentage of ferromagnetic materials such as iron and other valuable particles. These materials have very wide range of uses not only in industrial case but also in various constructive and laboratory works. Another very important point is to note that due to high percentage of iron present in the sand, many countries import sand for glass industries. It is known that the presence of iron in natural sand mixture increases the brittleness of glass [1]. So the target of this system is to refine the sand mixture and separate the ferromagnetic material from the mixture. This automated system is used to separate magnetic particles industrially. When minerals are placed in a magnetic field, there are three reactions which may occur. First, they are attracted 
to the magnetic field. Second, they are repulsed by the magnetic field. And third, no noticeable reaction to the magnetic field [2] occurs. Particles that are attracted to the magnetic field are called magnetic. But, there are two classifications of magnetic particles, strongly magnetic particles, such as iron and magnetite, and weakly magnetic particles, such as chromite and ilmenite. Strong magnetic particles may be easily separated with a separator having a low intensity magnetic field of 400-600 gauss (0.04-0.06T) [3]. Paramagnetic particles (weakly magnetic) require a higher intensity magnetic field to separate them, generally ranging from 6,000 to 20,000 (0.6 to $2 \mathrm{~T}$ ) gauss ( $1 \mathrm{~T}=10^{4}$ gauss). Particles that are repulsed by a magnetic field are called diamagnetic. A line of separators called Eddy Current Separators [4], takes advantage of the diamagnetic particles, separating them from other material. When product, such as aluminum, passes over the eddy current, the spinning magnets inside the shell generate an eddy current in the aluminum thus creating a magnetic field around the piece of aluminum. The polarity of the magnetic field of the aluminum is the same as the rotating magnets, causing the aluminum to be repelled away from the separator. An eddy current is defined as the currents caused by voltages induced by changing flux, and tend to oppose the change of the flux.

\section{OBJECTIVES}

The objectives of this system are to separate the magnetic particles from a solid-solid non-homogeneous mixture (sea sand) so that it can be used industrially and also to reduce the cost of separating process.

\section{MECHANICAL COMPONENTS}

The hardware part of the system covers the whole electrical system. The total mechanical structure is developed by the wood with shafts and steel plates, which gives a pictorial view of the whole separating process (Fig. 1).

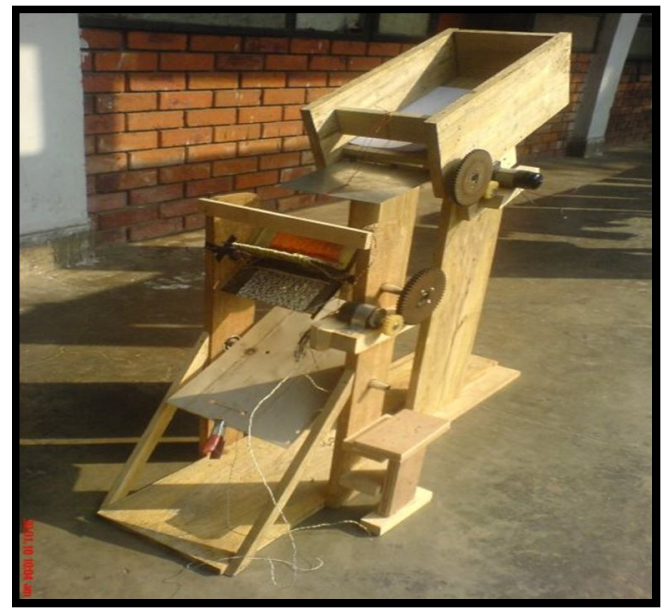

Fig. 1: Model of the overall system. 


\subsection{Wood}

Wood has been used here to develop the overall system. The wooden blocks are used to make the structure.

\subsection{Super Enamel Wire, Bearing and Copper Wire}

Super enamel wire (Fig. 2) is used for magnetization. Windings of the steel plates for electromagnet are made by this wire. Here ball bearing (Fig. 3) is used. It's been used in the crossing bar to reduce vibration and to rotate smoothly for creating an uniform magnetic field. It helps to rotate the shaft with the help of a motor. Insulated copper wire was used as the connecting wire.

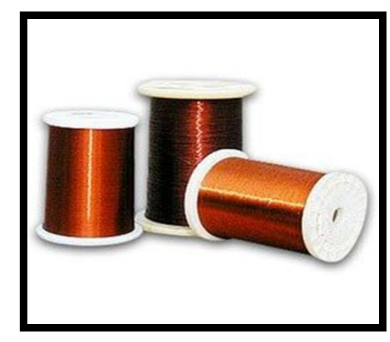

Fig. 2: Enamel wire.

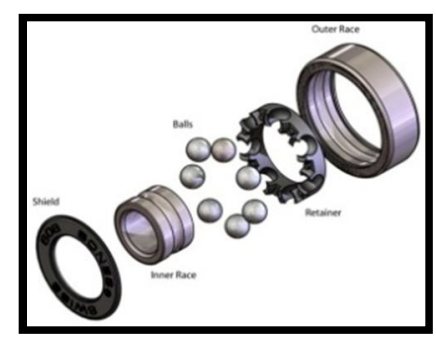

Fig. 3: Ball Bearing.

\section{ELECTRICAL COMPONENTS}

Electrical arrangement is also very important for this system. The electrical system is briefly described here.

\subsection{Gear Motor and Limit Switch}

Two gear motors are used here each of them rated 24V and 3amp. A limit switch is used to demagnetize the coil when the gate is closed.

\subsection{IC NE555}

NE-555 is an integrated circuit. It is a timer IC. It is highly stable for generating accurate time delay or oscillation. It can operate both as mono stable and astable multi vibrator [5]. In a mono stable mode, it can produce accurate time delay from microseconds to hours. In the astable mode, it can produce rectangular waves with a variable duty cycle. The IC NE-555 timer consists of two comparators, a flip-flop, a discharge transistor and a resistive voltage divider (Fig. 4). 


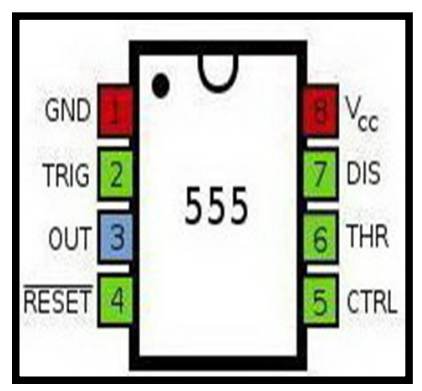

Fig. 4: Pin diagram of NE555.

\subsection{4013}

The CD4013B dual D flip-flop is a monolithic complementary MOS (CMOS) integrated circuit constructed with $\mathrm{N}$ - and P-channel enhancement mode transistors. Each flip-flop has independent data, set, reset, and clock inputs and " $Q$ " and ' $Q$ " outputs. These devices can be used for shift register applications, and by connecting " $Q$ " output to the data input, for counter and toggle applications. The logic level present at the " $\mathrm{D}$ " input is transferred to the Q output during the positive-going transition of the clock pulse. Setting or resetting is independent of the clock and is accomplished by a high level on the set or reset line respectively. Maximum speed of operation is $5 \mathrm{MHz}$, Voltage $\mathrm{V}_{\mathrm{CC}} 4.5$ to $15 \mathrm{~V}$, Current $\left(\mathrm{V}_{\mathrm{CC}}\right.$ $=+5$ V) 3 to $6 \mathrm{~mA}$, Maximum O/P Current 200mA, Power dissipation 600mW [5]. The CD 4013 can be used as a frequency divider in which the output is half the input frequency (Fig. 5). It can also be used in TOGGLE MODE (this is exactly the same as a frequency divider) where the output toggles ON then OFF after each clock (input pulse) [5].

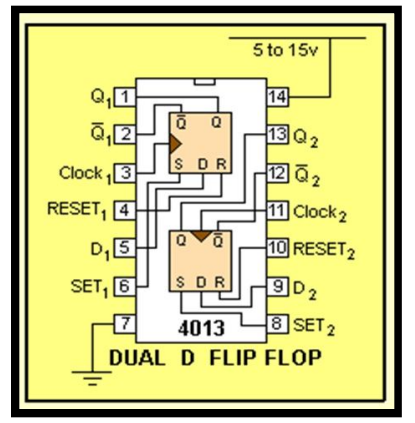

Fig. 5: Pin diagram of 4013.

\subsection{H-Bridge}

The H-Bridge (Fig. 6) is a special types of circuit by which the gear motor can be operated in clockwise or anti-clockwise direction. Here TIP 122, TIP 127 and BC 547 transistors are used. In the figure terminal A and B are connected with 4013. 


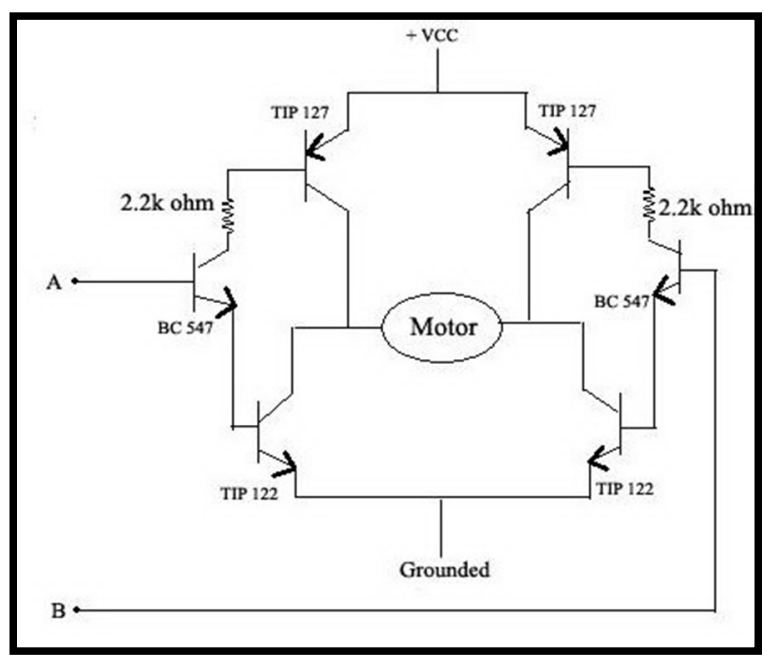

Fig. 6: Circuit schematic of H-Bridge.

\section{DESIGN METHODOLOGY}

The efective and simple mechanical design is an important part of this system. The whole mechanical part can be divided into three modules to make the description easier. The description of the three modules with diagrams is given below.

\subsection{Module 1}

Module 1 (Fig. 7) consists of a container to store non homogeneous solid-solid mixture. It was specially designed to deliver mixture discontinuously with a controlled flow rate. It delivers sand on the rotating electro-magnet of module 2 . The flow is controlled by a gate which is connected directly to the shaft. Power transmitted to this shaft from gear motor through gear and pinion. A circuit was used to inverse the rotation of the motor after a certain time interval for opening and closing of the gate. Again, module 1 is directly connected to module 3 and controls the direction of its movement.

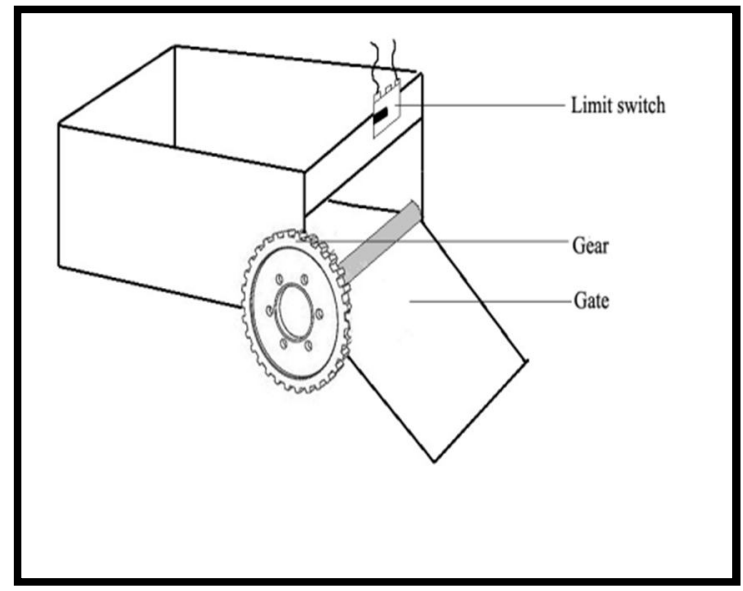

Fig. 7: Schematic of module 1. 


\subsection{Module 2}

The Module 2 (Fig. 8) consists of an electro-magnet which rotates due to the rotation of gear and pinion. Four steel sheets were connected to the shaft each within 90 degree separation and winding was given on each sheet for magnetizing it. For a certain time it remains magnetized and gets demagnetized for a while and thus this cycle of magnetizationdemagnetization continues. When magnetized, the rotating electro-magnet attracts the ferromagnetic particles present in the mixture. They get attached with the electro-magnet plates while filtered mixture was collected in a separate space. After a certain period of time, sand flow is stopped from module 1. At the same time the steel plates get demagnetized and the ferro-magnetic materials loose the attachment with these plates. Then module 3 is to collect the separated ferro-magnetic materials and filtered sand in different container.

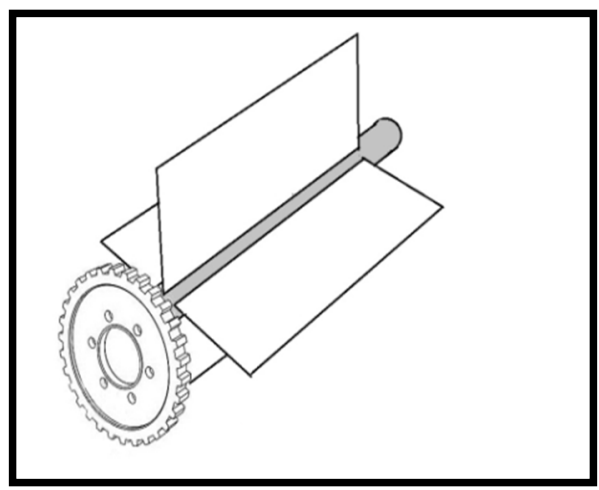

Fig. 8: Schematic of module 2.

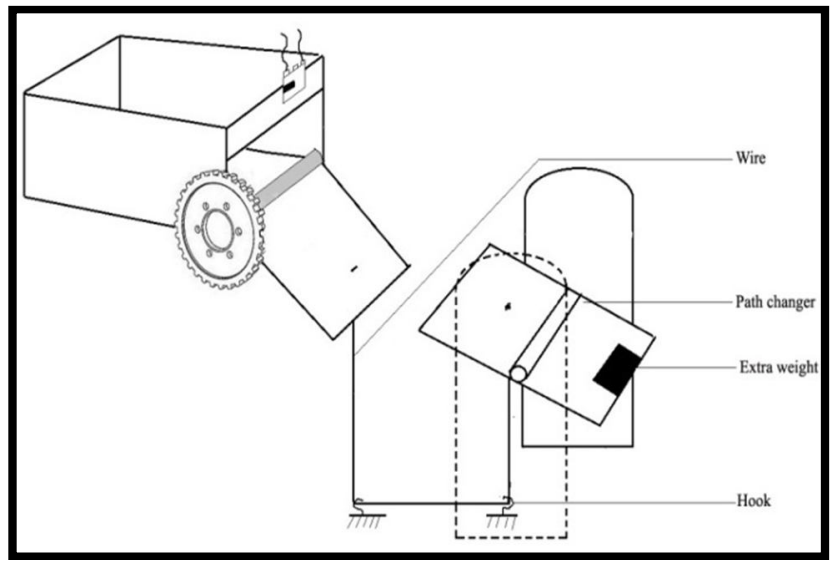

Fig. 9: Schematic of module 3.

\subsection{Module 3}

In module 3 (Fig. 9), a steel plate is connected to the shaft which is supported by the bearing and can rotate freely. This rotation is controlled completely by module 1 . A wire connects the gate of module 1 with one side of the steel plate of module 3. Normally, the plate stays inclined on one side because of extra weight on that side. So when the gate remains open, sand falls on the electro-magnet and then goes through the inclined plate to the filtered sand collector. Again, when the gate is closed, due to the tension of the wire the plate becomes inclined on the other side. And at the same time the electro-magnet loose attraction 
and falls through the steel plate to the ferromagnetic magnetic material collector. Thus the cycle of path changing continues.

\section{CIRCUIT CONFIGURATION}

A very simple circuit is used here. This circuit is basically divided into three parts. Part 1 is a timer circuit while part 2 is an $\mathrm{H}$-bridge and part 3 is a switch which is used to demagnetize the electro-magnet when the gate is closed or open.

\subsection{Part 1}

In the $1^{\text {st }}$ part, NE 555 IC and CD 4013 are used. NE 555 has 8 PIN. It is a timer IC which generates square wave pulse after a definite time interval. The time interval can be changed by changing the capacitance in Pin 5 and Pin 2.CD 4013 IC is a counter IC. It is a dtype flip-flop. It also generates square wave in Pin1 and Pin 2. When Pin1 is on, Pin 2 is off and vice versa. That means it gives output 10 or 01 .

\subsection{Part 2}

The Part 2 is an H-bridge which changes the rotation of the motor at a certain interval. It consists of 6 transistors. Among them, 2 are TIP 122, 2 are TIP 127 and 2 are BC 547. The rotation control of the gear motor for the H-Bridge is described below- there are four switching elements within the bridge. These four elements are often called, high side left, high side right, low side right, and low side left (when traversing in clockwise order). The switches are turned on in pairs, either high left and lower right, or lower left and high right, but never both switches on the same side of the bridge. If both switches on one side of a bridge are turned on it creates a short circuit between the plus and minus terminals (Fig. 10).

\begin{tabular}{|c|c|c|c|c|}
\hline $\begin{array}{l}\text { High } \\
\text { Side } \\
\text { Left } \\
\text { On }\end{array}$ & $\begin{array}{l}\text { High } \\
\text { Side } \\
\text { Right } \\
\text { Off }\end{array}$ & $\begin{array}{l}\text { Lowex } \\
\text { Left } \\
\text { Off }\end{array}$ & $\begin{array}{l}\text { Lowex } \\
\text { Fig ht } \\
\text { On }\end{array}$ & $\begin{array}{l}\text { Quadrant } \\
\text { Description } \\
\text { Wotor goes } \\
\text { Clockwise }\end{array}$ \\
\hline Off & On & On & Off & $\begin{array}{l}\text { Mator goes } \\
\text { Counter- } \\
\text { clack wise }\end{array}$ \\
\hline On & On & Off & Off & $\begin{array}{l}\text { Motor } \\
\text { "brakes" } \\
\text { and } \\
\text { decelerates }\end{array}$ \\
\hline Off & Off & On & On & $\begin{array}{l}\text { Motor } \\
\text { "brakes" } \\
\text { and } \\
\text { decelerates }\end{array}$ \\
\hline
\end{tabular}

Fig. 10: Gear motor control in both directions by H-Bridge.

\subsection{Part 3}

It consists of a limit switch. The switch contains three pin. It is used to demagnetize the electro-magnet when the gate is closed. Normally the switch remains on. When the gate of the container is closed, it hits the switch and it makes the circuit open. 


\section{SYSTEM EVALUATION}

This magnetic separation method exploits the difference in behavior of particles in magnetic fields. This separation process is controlled more or less by four parameters. They are- Intensity of magnetic field, particle magnetic susceptibility, effective medium viscosity and particle velocity. In the International Unit System (SI) magnetic susceptibility is dimensionless and is denoted as $\chi$. More frequently [6] a specific magnetic susceptibility $\left(\chi_{\mathrm{w}}\right)$ is used and is defined as in (1):

$$
\chi_{\mathrm{w}}=\chi / \rho
$$

Here, $\rho$ is the density of the material. The specific magnetic susceptibility $\chi_{w}$ is expressed in $\mathrm{cm}^{3} / \mathrm{g}$. There are other forms of susceptibilities including molar magnetic susceptibility $\chi_{\mathrm{M}}$. Materials, which are repelled from the magnetic field are called diamagnetic and have negative values of the magnetic susceptibility. Particles attracted towards greater intensity of the magnetic field are called paramagnetic. Magnetic separation is based on principle that the force (F) acting [7] on a particle is given by the simplified form (2)

$$
F_{x}=\mu_{0} \chi_{w} m\left(H_{x} \frac{\partial H_{x}}{\partial x}\right)
$$

where,

$F$ - Magnetic force, $\mathrm{N}$

$\mu_{0}-\quad$ Magnetic permeability of vacuum

$\chi_{w}-\quad$ Specific magnetic susceptibility, $\mathrm{cm}^{3} / \mathrm{g}$

$\mathrm{m}-\quad$ Mass of particles, $\mathrm{g}$

$H$ - Magnetic field intensity, $\mathrm{A} / \mathrm{m}$

$\frac{\partial H_{x}}{\partial x}$ - Field gradient, $\mathrm{A} / \mathrm{m}^{2}$

The paramagnetics are further divided into such categories as true paramagnetic, ferromagnetic, and ferri and anti-ferromagnetic. Their affiliation is determined by the behavior in changing magnetic field [8] (Fig. 11) and temperature [9] (Fig. 12). Magnetization is expressed by M [10] (3).

$$
\mathrm{M}=\rho \cdot \chi_{w} \cdot \mathrm{H}
$$

Here four separate rectangular current carrying coils (sheets) are used. The magnetic field produced for this separation process is around $0.1 \mathrm{~T}$. The field can easily be increased by increasing the number of rectangular sheets as well as the coils. The magnetic separation process consists of several steps (Fig. 13). In every step [11] different types of mineral fractions [12] are produced (Fig. 14). 


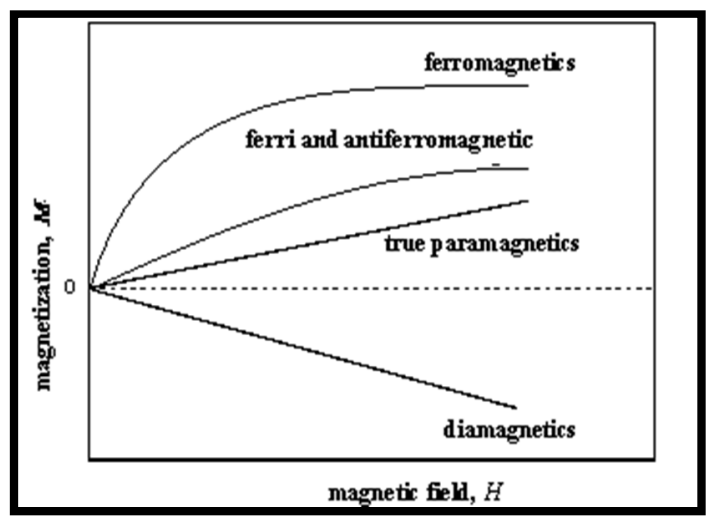

Fig. 11: Magnetization versus magnetic field for different materials.

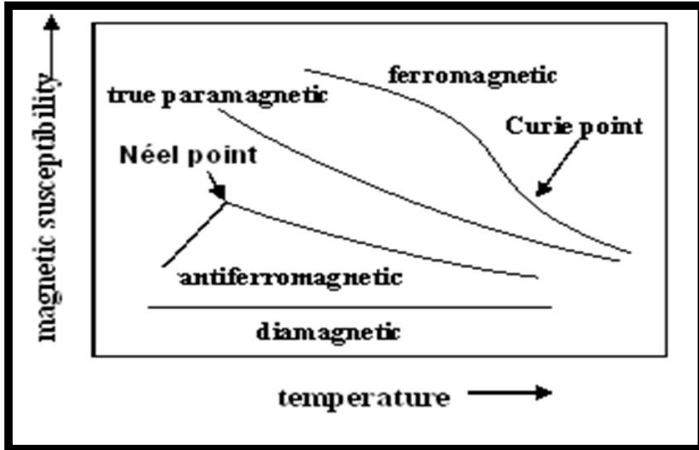

Fig. 12: Magnetic susceptibility versus temperature for different materials.

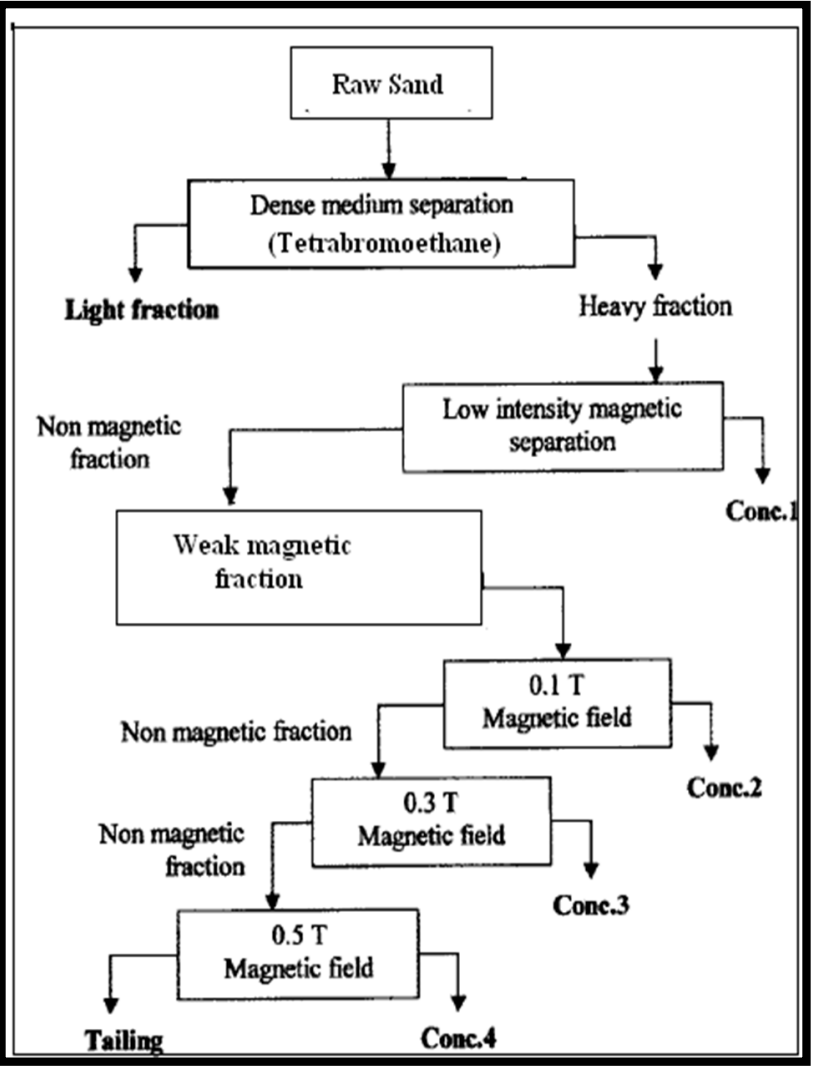


Fig. 13: Separation steps of sand at different magnetic field strength.

\begin{tabular}{|ll|}
\hline \hline Mineral fraction & Mineral phases (types of minerals) \\
\hline Light fraction & Quartz $\left(\mathrm{SiO}_{2}\right)$ \\
Conc.1 & Magnetite $\left(\mathrm{Fe}_{3} \mathrm{O}_{4}\right)$, ilmenite $\left(\mathrm{FeTiO}_{3}\right)$ \\
Conc.2 & Ilmenite $\left(\mathrm{FeTiO}_{3}\right)$ \\
Conc.3 & Ilmenite $\left(\mathrm{FeTiO}_{3}\right)$, Pseudorutile $\left(\mathrm{Fe}_{2} \mathrm{Ti}_{3} \mathrm{O}_{9}\right)$ \\
Conc.4 & Ilmenite $\left(\mathrm{FeTiO}_{3}\right)$, Pseudorutile $\left(\mathrm{Fe}_{2} \mathrm{Ti}_{3} \mathrm{O}_{3}\right)$ \\
Tailing & Rutile $\left(\mathrm{TiO}_{2}\right)$, zircon $\left(\mathrm{ZrSiO}_{4}\right)$ \\
\hline \hline
\end{tabular}

Fig. 14: Different types of mineral fraction in sand processing.

To use the purified sand for the industrial purpose it is necessary to determine titanium and iron content in the different types of fractions. Mineral fractions are decomposed by fusion with $\mathrm{KHSO}_{4}$ at $800{ }^{\circ} \mathrm{C}$ and then dissolved in $20 \% \mathrm{H}_{2} \mathrm{SO}_{4}$ acid for further chemical assessment [13]. In sand (unpurified) generally two types of oxides are available [14]-Iron and titanium oxides (ilmenite and chromite). The magnetic susceptibility of chromite (Fig.15) and ilmenite (Fig.16) increases with increasing of iron content.

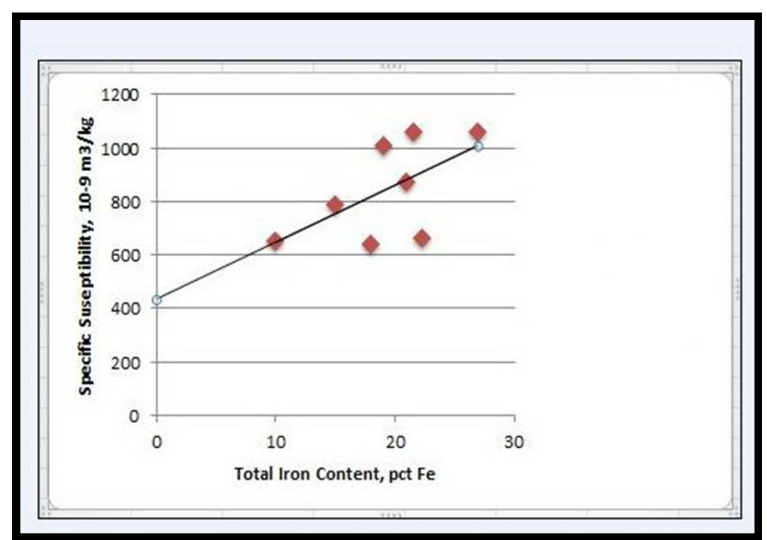

Fig. 15: Magnetic susceptibility versus iron content at lower temperature for chromite.

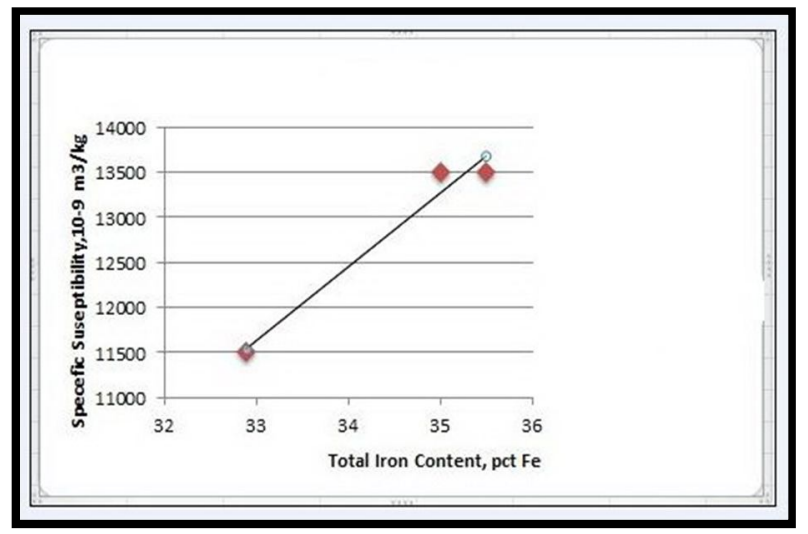

Fig. 16: Magnetic susceptibility versus iron-content (at lower temperature) for ilmenite. 


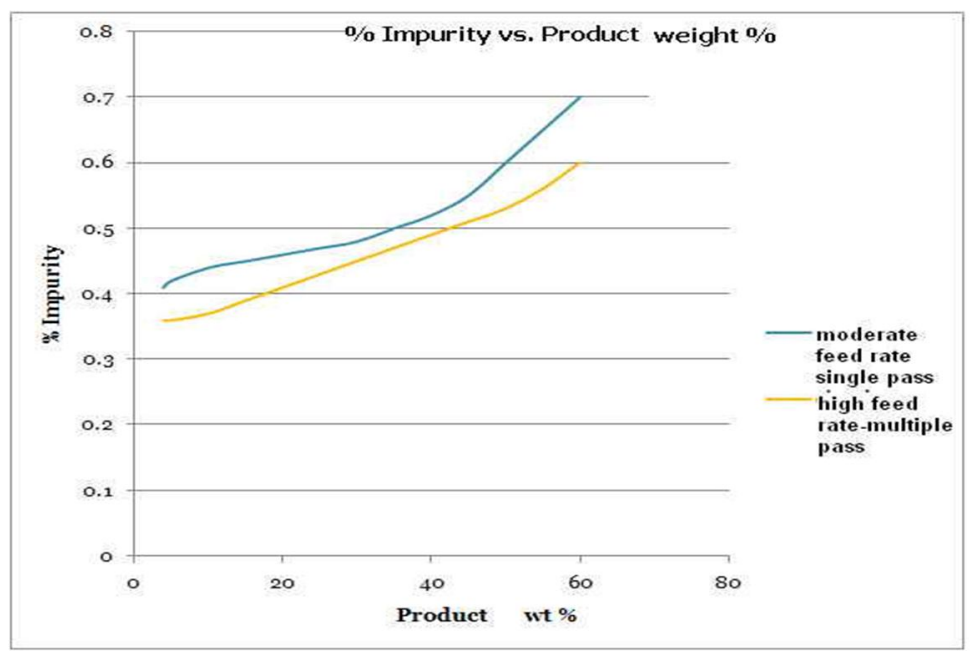

Fig. 17: Impurity versus output product in percentage by weight.

Ilmenite $\left(\mathrm{FeTiO}_{3}\right)$ has the magnetic susceptibility of $200-1500 \times 10^{-6} \mathrm{~cm}^{3} / \mathrm{g}$. The magnetic susceptibility of Iron $(\mathrm{FeO})$ and Titanium $\left(\mathrm{TiO}_{2}\right)$ oxides are respectively +7200 and +5.9 $\mathrm{cm}^{3} /$ mole. Velocity as well as the size of the particles is also important parameters for magnetic separation. A low velocity enables the magnetic field to capture and hold a particle, whereas a high velocity causes only a deflection and no capture. This effect is more important as magnetic susceptibility decreases. In figure 17 the data is shown for the \% Impurity (measured in weight) Vs. \% refined Product (sand). It can also be seen that high feed rate multiple pass is more effective than the moderate feed rate single pass. Here a gear-pinion (Fig. 17) mechanism is introduced to control the velocity of the particles by setting the sand container at a certain angle. With this mechanism the container position is controlled by a connecting rod. Particles size less than $355 \mu \mathrm{m}$ is economical for the separation technique [15].

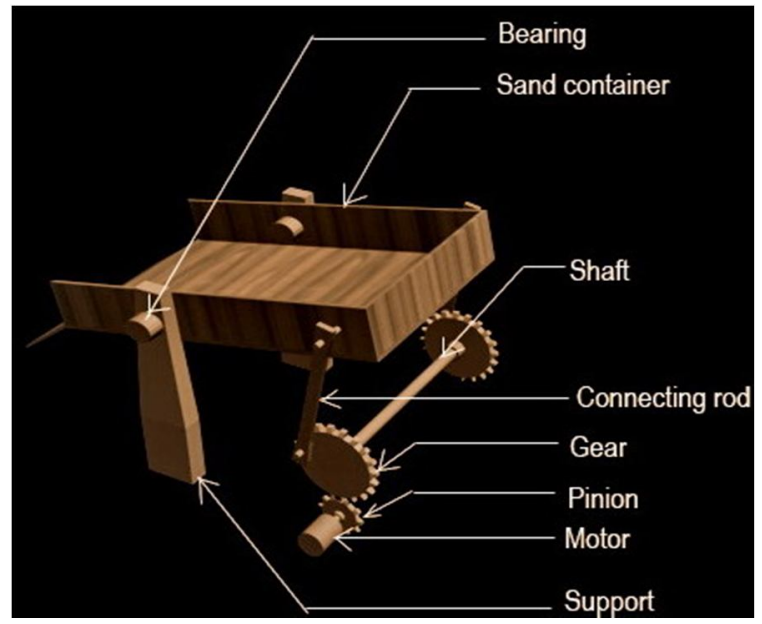

Fig. 18: Velocity control of the particles by changing the angle of the container.

The magnitude of the magnetic force of a particle in a magnetic field depends in part upon the magnetic susceptibility of the particle. If two minerals of equal volume but different 
susceptibilities are exposed to the same magnetic field and field gradient, the resulting difference in magnetic forces will result in a separation of the particles if enough time is allowed. Magnetic separation is generally a low cost method of recovery, unless high intensity separators are required. The electro-magnetic high intensity separators that produce 20,000 gauss (2T), is expensive. However, Iron oxides and Titanium oxides can be easily separated from sea sands by this magnetic separation process. Because for this separation process magnetic fields only around 3,000 gauss (0.3T) is needed [16] and so it is inexpensive. But when looking for a process to recover valuable minerals, magnetic separation should not be overlooked, if some of the material is magnetic or Para-magnetic. Because that time a huge magnetic field around $2 \mathrm{~T}$ is needed.

\section{CONCLUSION}

Here the concentration is to reduce the cost for separating the magnetic particles in sand processing. This automated magnetic separation system is fabricated with a simple mechanical design using locally available materials. That is why the process reduces the cost as well as increases the efficiency.

\section{ACKNOWLEDGEMENT}

This work was supported by Control and Instrumentation lab of Bangladesh University of Engineering and Technology (BUET).

\section{REFERENCES}

[1] U.O. Häfeli, W. Schütt, J. Teller, et al. (Eds), "Scientific and Clinical Applications of magnetic Cariers", New York, 1997.

[2] J. Svoboda, "Magnetic methods for the treatment of minerals", Elsevier, 1987, pp.692.

[3] Journal of Magnetism and Magnetic Materials, 262 (2003), pp. 269-279.

[4] R. M. Staude , Z. Schlett, M. Lungu and D. Baltateanu, "A new possibility in eddy-current separation”, Minerals Engineering, 15(2002),pp. 287-291.

[5] http://www.alldatasheet.com.

[6] Journal of Magnetism and Magnetic Materials, 262 (2003): 269-279

[7] U. K. Veeramachaneni , R.L. Carroll , "Magnetic Particle Motion in a Gradient Field" , Proceedings of the COMSOL Conference 2007, Boston

[8] Xun-Fang Sun, Xiao-Shu Fang, Yao-Hong Lu, "Strength of Materials", People's Education Publisher, Beijing. Sept. 1964

[9] N. Ali, I.S. Dubenko, I.Y. Gaidukova, A.S. Markosyan, V.E. Rodimin, "Temperature induced magnetic instability in the itinerant Co subsystem of the Er1-xYxCo3 compounds", Physics B 281\&282 (2000), pp. 696-698.

[10] Journal of applied physics, vol. 93, no. 1015, May 2003.

[11] N. Fraunholcz, P.C. Rem and P.A.C.M. Haeser, "Dry magnus separation, Minerals Engineering", 2002, pp. 45-51.

[12] J. Mendham, R.C. Denney, J.D. Barnes and M.J.K. Thomas, "Textbook of Quantitative Chemical Analysis", 6th Edn, England, 2000, pp. 669-670. 
[13] P.G. Jeffery and D. Hutchison, "Chemical Method of Rock Analysis", 3rd Edn., Pergamon, Oxford, 1981, pp. 21-22, pp. 346-348

[14] M. Dobbins, J. Domenico and P. Dunn, "A discussion of magnetic separation technique for concentrating ilmenite and chromite ores", International Heavy Minerals Conference, Southern African Mining and Metallurgy,2007, pp. 197-204.

[15] F. Frass , "Magnetic Separation of Minerals of low susceptibiity and small particle size", Bumines IC 8383, 1968, pp. 11-12.

[16] U.T. Andres, "Magnetohydrodynamic and Magnetohydrostatic Methods of Mineral Seperation", Wiley, 1976, pp. 206-218. 